\title{
La apropiación paisajística del territorio: una disputa epistemológica
}

\section{The territory landscape appropriation: an epistemological dispute}

Francisco Covarrubias-Villa (pancheco@prodigy.net.mx) Centro Interdisciplinario de Investigación para el Desarrollo Integral Regional, Unidad Michoacán, Instituto Politécnico Nacional (Jiquilpan, México) http://orcid.org/0000-0003-1728-0080

Ma. Guadalupe Cruz-Navarro (lupitacruz63@hotmail.com) Centro Interdisciplinario de Investigación para el Desarrollo Integral Regional, Unidad Michoacán, Instituto Politécnico Nacional (Jiquilpan, México) http://orcid.org/0000-0002-1333-4152

\begin{abstract}
The objective is to describe different landscape approaches. To carry this out, multiple information sources were analysed, recorded and discussed, selecting the most expressive approaches of the theoretical rationality from which the landscape is conceived. It was found that having the painting landscape born in the Middle Ages, it is studied today by aesthetics as an artistic representation, as a geosystem by geography, as an ecosystem by ecology and as a subjective appropriation of the territory by sociology, anthropology and semiotics. However, the contemplative landscape experience was predominantly carried out under aesthetic form, but it is not a perspective sufficiently attended. Alongside with the artistic representation of the landscape, constitutes the most reliable perspective of the landscape concept.
\end{abstract}

Key words: appropriation, territory, landscape, experience, aesthetics.

\section{Resumen}

El objetivo de la investigación es describir las diferentes maneras de concebir el paisaje. Para ello, fueron analizadas, fichadas y discutidas múltiples fuentes de información, seleccionándose los planteamientos más expresivos de la racionalidad teórica desde la cual el paisaje es concebido. Se encontró que, habiendo nacido el paisaje de la pintura de la Edad Media, hoy día es estudiado como representación artística por la estética, como geosistema por la geografía, como ecosistema por la ecología y como apropiación subjetiva del territorio por la sociología, la antropología y la semiótica. Pero la experiencia paisajística contemplativa realizada predominantemente bajo formas estéticas no es una perspectiva suficientemente atendida a pesar de que, junto con la representación artística del paisaje, constituye la perspectiva más fidedigna del concepto de paisaje.

Palabras clave: apropiación, territorio, paisaje, experiencia, estética.

\section{Introducción}

En libros y artículos científicos el paisaje es predominantemente tratado como relaciones entre objetos existentes en un territorio. Si la relación se establece entre objetos geofísicos el "paisaje" es geosistema; 
si la relación es entre seres bióticos y abióticos es ecosistema. Otra manera de concebir el paisaje es como conjunto de representaciones subjetivas del territorio. Sin embargo, el paisaje se originó en el arte y concretamente en la pintura de la Edad Media, por lo que se le puede atribuir una esencia estética y un carácter fenomenológico por tratarse de la relación de un sujeto con un territorio representado o real.

Paisaje es un concepto referido a figuras de pensamiento estéticamente construidas en las que se alude un territorio y, sin embargo, es investigado predominantemente como sustrato material despojándosele de su carácter subjetivo y reduciéndosele a relaciones entre objetos geofísicos o ecosistémicos, cuando en realidad se trata de una construcción subjetiva vinculada a un sustrato material.

Por otra parte, la representación artística del territorio ha sido tradicionalmente objeto de la estética, en tanto que la experiencia paisajística contemplativa no ha sido de su interés, a pesar de su enorme presencia como fenómeno social. Los estudios de la apropiación subjetiva del territorio por las comunidades humanas se realizan utilizando criterios que dan cuenta del significado ideológico, económico, político o religioso que el territorio tiene en los individuos, pero no cuando se trata de una apropiación paisajística del territorio con referentes estéticos de manera predominante, que es el caso genuino de la construcción paisajística, junto con su representación artística en la pintura, la fotografía, la literatura y el cine.

La investigación realizada permitió identificar la existencia de diversos conceptos de paisaje: i) representación artística, ii) experiencia estética contemplativa, iii) territorio, iv) geosistema, v) ecosistema y vi) apropiación subjetiva del territorio. Para algunos autores el uso científico que la geografía y la ecología hacen del concepto estético de paisaje lo pervierte. No se trata de una perversión producto del uso de un concepto generado en un modo de apropiación de lo real diferente, sino de concepciones ontoepistemológicas diferentes pertenecientes a racionalidades teóricas distintas. Sin embargo, la experiencia estética paisajística contemplativa es la menos estudiada dada su filiación epistemológica a la estética.

Paisaje es una herramienta que nace para denominar el territorio representado artísticamente en la pintura de finales del siglo XV o a principios del XVI y de ahí tomada por la geografía y la ecología para expresar la dimensión ontológica de sus objetos de estudio. El paisaje no es el sustrato material de la apropiación estética de un territorio, sino el fenómeno constituido por la relación estética subjetiva que el sujeto establece con el sustrato material del territorio como unidad y no la figura de pensamiento o el sustrato material por separado. Incluso posturas holísticas como la de Fernández Álvarez se resisten a estudiar el paisaje desde esta perspectiva. Dice: "Una de las virtudes más significativas del territorio, especialmente en un espacio de montaña, es su paisaje, elemento éste que, 'a ojos humanos', es capaz de caracterizar una zona por su belleza, por sus formas, es decir, 'el paisaje es lo que permite definir la 'personalidad' geográfica de los lugares'; por lo tanto es necesario saber interpretarlo, cuáles son los elementos que lo componen, cómo se interrelacionan entre sí, cuál es su dinámica, para así estar en disposición de valorarlo por su calidad intrínseca y no solo por su belleza, cualidad esta de notable subjetividad sujeta a la interpretación del individuo" (Fernández Álvarez 2013:102).

La dimensión íntima, emocional y sentimental de la apropiación paisajística va acompañada de una figura estética de pensamiento totalizadora del territorio: "La naturaleza se representa en nuestra mente con sus distintos detalles: los campos, los árboles, los riachuelos, la roca, las flores, la cumbre herbosa. Nos encontramos frente a una propia fisonomía espiritual que responde a la gama de nuestras emociones y nuestros sentimientos. Pero advertimos, en nuestra conciencia, que existe algo que supera aquel vasto panorama de elementos separados. Ese algo es el aura de una totalidad que envuelve y se infiltra, 
ininterrumpida fluctuación de datos y células perceptivas, irradiación sentimental. Ese algo es el paisaje. Es más que los fragmentos individuales de nuestra mirada quebrada por lo ritmos de la percepción psicológica. El paisaje es una infinita concatenación de las formas que siempre se modela y reinventa a partir de la historia, pero también del individuo. El ser humano, de hecho, sabe componer, casi por instinto, efectos y fuerzas del tiempo y del espacio unidos en una danza perpetua de líneas y superficies" (Milani 2008:53).

\section{Metodología}

El proceso de investigación inició con la delimitación del objeto de investigación, contando con la información proporcionada por la ejecución de dos proyectos de investigación, el clave SIP 20150430 denominado: La relación sujeto-objeto en la teorización del paisaje y el SIP 20170704 denominado La apropiación paisajística del territorio. Con base en la discusión de esta información se determinó el nuevo problema a investigar el cual quedó delimitado de la siguiente manera: Condiciones en las que se realiza el modo artístico de apropiación de lo real y las apropiaciones paisajísticas creativa y contemplativa. Después se diseñó un esquema de investigación en el que se establecieron los ámbitos de indagación necesarios para construir el conocimiento del objeto de investigación, que fueron los siguientes: 1 . Modos de apropiación de lo real y formas de la conciencia, 2. Apropiación paisajística artística creativa y 3. Apropiación paisajística contemplativa. Luego se determinaron las fuentes de información para cada uno de los ámbitos del esquema de investigación, identificándose y seleccionándose en total 14 artículos y 63 libros; las fichas de trabajo de las fuentes ya analizadas se integraron en la base electrónica de fichas de trabajo de la investigación y se procedió al análisis y fichado de las fuentes de información faltantes.

El proceso de exposición de resultados de la investigación inició con el diseño del esquema de exposición el cual quedó constituido por los siguientes apartados: 1. Sensaciones y sentimientos, 2. La apropiación histórico-social del territorio, 3. La apropiación paisajística y 4. El paisaje: experiencia estética contemplativa. Las fichas de trabajo relevantes fueron codificadas de conformidad con éste y; por último, el esquema de exposición se fue particularizando al mismo tiempo que el código con el que las fichas de trabajo fueron seleccionadas hasta convertirse en guion de redacción y con base en él se elaboró el escrito del cual se extrajo el presente artículo.

\section{La apropiación social del territorio}

Los miembros de la entidad comunitaria mantienen una relación unitaria con la naturaleza; el ser humano es naturaleza. Las comunidades toman los satisfactores de la naturaleza y, al hacerlo, se apropian de un territorio, independientemente de que se trate de comunidades nómadas que establecen itinerarios cíclicos o de comunidades sedentarias. Entre mayor es el estado animal de los individuos que constituyen una comunidad humana, mayor es la determinación que ejercen los elementos naturales sobre ellos y menor el impacto de su actividad sobre el territorio. Sin embargo, las necesidades de los humanos (aun en su estado más primitivo) son necesidades sociales a pesar de provenir directa e inmediatamente de su estado animal. En la medida en la que se incrementan las relaciones entre los miembros de una comunidad y con el resto de la naturaleza, mayor es el poder de transformación y acondicionamiento del territorio para la satisfacción de las necesidades sociales de los individuos y menor la determinación que los elementos de la naturaleza ejercen sobre el ser humano, sin que esta determinación desaparezca nunca.

La complejización de las relaciones sociales genera la división del trabajo y ésta la diversificación de las afectaciones del territorio, sin implicar en su primer momento la ruptura de la unidad humana con la 
naturaleza, la cual se mantuvo hasta la aparición del modo artístico de apropiación de lo real en las formaciones sociales clasistas. La ruptura de la unidad ser humano-naturaleza no destruye el carácter transformador del territorio por el ser humano, sino que, por lo contrario, lo estimula. La naturaleza ya no se explota para satisfacer necesidades elementales de sobrevivencia de los individuos, sino para generar excedentes que permitan el sostenimiento de un grupo creciente de sujetos que no participan directamente en la obtención de satisfactores de la naturaleza y, posteriormente, de individuos que no participan en el proceso de producción y que son los que más satisfactores acaparan y consumen.

La actividad práctica productiva del ser humano se expresa como apropiación material de la naturaleza en un lugar, en un territorio. El ser humano construye socialmente el territorio transformando la naturaleza de conformidad con la satisfacción de las necesidades que culturalmente va adquiriendo y que, muchas de ellas, poseen un sustrato físico-biológico. Al hacerlo, va plasmando en el territorio su concepción de lo real, sus aspiraciones, sus anhelos y los artificios que requiere para vivir. En cambio, la apropiación paisajística del territorio surge como necesidad de satisfacción de una necesidad estética en la que la única transformación es la consistente en el tránsito de sustrato material territorial a emoción.

La apropiación del territorio como lugar de paso, de asentamiento temporal o de asentamiento permanente es producto de la organización social interna de la comunidad humana y de las decisiones tomadas por otras comunidades. En la etapa nómada el ser humano se apropia de los satisfactores tal como los encuentra en la naturaleza y establece itinerarios temporales con base en la disponibilidad de satisfactores en cada región. Su organización social corresponde con la estrategia de obtención de satisfactores y el territorio apropiado por la comunidad está integrado por los lugares ocupados en su recorrido. La decisión de sedentarización seguramente se debió a la existencia permanente de satisfactores durante más de dos estaciones del año, lo cual representó una transformación en la organización social y en el proceso de trabajo.

La sedentarización trajo consigo la apropiación comunal exclusiva del territorio, la agricultura y la guerra cuando el territorio apropiado quería ser ocupado temporalmente por una comunidad nómada. La sedentarización de una comunidad obligó a otras a proceder de manera semejante a ella y entre más comunidades se asentaban mayor era la presión para aquellas que se mantenían en estado nómada. Las comunidades nómadas consideraban una agresión que otra comunidad ocupara permanentemente el territorio que ellas habitaban de manera temporal; las comunidades sedentarias consideraban una agresión que una comunidad nómada reclamara la ocupación temporal del territorio en el que ella se había asentado. Surge la guerra y con ella la aparición de un grupo social crecientemente dedicado a la defensa de la comunidad y finalmente profesionalizado y convertido en clase social privilegiada que no participaba directamente en el proceso de producción de satisfactores: la milicia. En la medida en la que se va complejizando la estructura social va aumentando el número de individuos que no participan directamente en la producción de satisfactores, pero sí en su consumo. Estos grupos sociales "parasitarios" van incrementando la exigencia de calidad y cantidad de sus satisfactores hasta llegar a un momento histórico en el que se requiere de grandes masas de trabajadores para producir los satisfactores que esto sujetos requieren.

La relación ser humano-naturaleza se va modificando y en la medida en que va aumentando el dominio del ser humano sobre la naturaleza, se va acelerando la utilización de ésta como satisfactor de necesidades práctico-utilitarias, agregando posteriormente la satisfacción de necesidades de orden mágico-religioso, artístico y científico. La explotación creciente de la naturaleza por el ser humano va transformándola. El 
territorio es cada vez más producto de la acción humana y el ser humano el más importante generador de su morfología.

El desarrollo de una comunidad genera necesidades que la empujan más allá de su territorio y la conducen a invadir material o subjetivamente otros territorios. Las fuerzas sociales existentes en el interior de una comunidad son aplastadas por la comunidad conquistadora o por uno o algunos de los grupos sociales que la constituyen, al aliarse éstos con las nuevas fuerzas dominantes e integrándose a su proyecto cultural.

La universalización es consustancial al régimen capitalista: universalización de los satisfactores como mercancía y universalización del capitalismo como modo de producción en todo el planeta. De manera creciente, las necesidades humanas están siendo satisfechas por mercancías y la mayoría de las naciones del mundo van asumiendo el modo capitalista de producción como organización político-social. La universalización de la mercancía contiene dos aspectos: i) la conversión de los satisfactores en mercancía y ii) la universalización de la necesidad y de la mercancía que la satisface. Así, en la medida en la que una necesidad se asume en mayor número de regiones y naciones del mundo, mayor es el volumen de su producción, mayor es el consumo absoluto de componentes de la naturaleza utilizado para su producción y distribución y menor es el costo de éstas dos últimas.

La universalización de la mercancía y de las necesidades implica un grado muy elevado de homogenización de las conciencias, lo cual incluye la interiorización de una enorme cantidad de modelos existenciales como personalidad, objetos, conductas, ideales, proyectos personales, estructuras políticas, relaciones sociales, etc., subrepticiamente introducidos en los individuos para que sean tomados por estos como inmanentes. "La sobreeconomización del mundo induce la homogeneización de los patrones de producción y de consumo, y atenta contra un proyecto de sustentabilidad global fundado en la diversidad ecológica y cultural del planeta" (Leff 2004:112). Esto se traduce en reproducción de criterios paisajísticos entre la población y en la multiplicación territorial de remedos de los modelos estandarizados de paisaje socializados.

Se estandariza la alimentación, el vestido, los sistemas de comunicación, la vivienda, los estudios y cada día aumenta más y más el número de individuos semejantes, cosificados, estandarizados también. En todo el mundo se encuentran semejantes centros comerciales, hoteles, escuelas, jardines, parques ecológicos, estadios deportivos, carreteras, postes, cabañas y casas que dan cuenta de una cultura común en muchos de sus aspectos. En este proceso de estandarización de territorios participa la mayoría de la población, pero la decisión es tomada por los grandes empresarios, los gobernantes y los profesionales a su servicio.

La atribución de significados a los elementos del paisaje es producto del lugar que ocupa en la sociedad el sujeto, por lo que diferentes sujetos se apropian diferencialmente del mismo territorio en el mismo momento, o bien, el mismo sujeto se apropia de maneras diferentes del territorio en momentos distintos, aun en los "paisajes residuales" señalados por Nogué (2011:6). La apropiación individual del territorio es social debido a las condiciones en las que se realiza el proceso de constitución de su conciencia, sin que ello implique la construcción de figuras de pensamiento idénticas del mismo territorio por diferentes sujetos.

Pero más allá de los rasgos específicos de cada figura de pensamiento construida, el territorio apropiado subjetivamente aparece como totalidad y no como agregación de objetos, si bien algunos de éstos puedan resaltar en el panorama general. "Es el cuadro conjunto el que caracteriza al paisaje. El sentimiento del paisaje significa precisamente lo general de ese paisaje, no la sensación efímera ni lo que corresponde a 
algún elemento particular del mismo" (Gómez 2008:16). Se trata del concurso de formas múltiples proporcionadas por los objetos para constituir una forma total. La riqueza de la figura de pensamiento construida depende también de la riqueza de la estructura de la conciencia del sujeto; los matices, texturas y tonalidades de la figura construida tienen que ver más con el contenido de la conciencia que con las características del territorio apropiado, si bien el territorio debe poseer formas que estéticamente sean consideradas socialmente como bellas.

Dice Martínez que el habitante "crea el paisaje no solo porque lo construye materialmente, sino porque lo idea como tal paisaje, porque interpreta su territorio como paisaje" (2014:417), pero no es así: el habitante construye el territorio con base en los modelos que le han interiorizado, y no necesariamente se lo apropia paisajísticamente porque no siempre cuenta con los referentes artísticos requeridos para ello. "Al crear y recrear los paisajes a través de signos con mensajes ideológicos se forman imágenes y patrones de significados que permiten ejercer el control sobre el comportamiento, dado que las personas asumen estos paisajes 'manufacturados' de manera natural y lógica, pasando a incorporarlos a su imaginario y a consumirlos, defenderlos y legitimarlos" (Nogué 2007:12).

El Convenio Europeo del Paisaje asume una definición jurídico-política de paisaje que ha sido convertida en concepto en el ámbito académico-científico que lo ha empobrecido. Si todo territorio es paisaje independientemente del modo en el que es apropiado por el sujeto, la diferencia entre el sustrato material y la figura de pensamiento de él construida desaparece. El propio Nogué incurre en este error cuando afirma que "cada cultura -y también una misma cultura en diferentes períodos históricos- crea sus peculiares interpretaciones ante el paisaje en general y ante determinados elementos significativos del mismo. A su vez, en esa misma cultura se darán diversas lecturas del paisaje en función de los diferentes grupos sociales y culturales existentes" (2008:12).

El territorio es identitario independientemente de que el sujeto construya o no una figura paisajística del territorio que habita. Es identitario porque la vida cotidiana la desarrolla el sujeto en un territorio dejando su huella en él. Pero no solo existe la marca del sujeto en el territorio, sino también la marca del territorio en el sujeto. El territorio habitado incide en el desarrollo de determinadas sensibilidades, en la construcción de proyectos existenciales, en la conservación de nostalgias y añoranzas. Como dice Zusman: "tanto la nostalgia por el pasado como el interés por conservar una naturaleza aparentemente prístina, desembocan en procesos de construcción de paisajes. A partir de aquí, ciertos lugares son considerados dignos de preservación, se tornan bienes escasos y entran en la pugna por la apropiación social. La naturaleza y la historia valorizadas estéticamente en forma diferencial en el espacio se conforman, como nunca antes, en un ámbito de conflicto social" (Zusman 2008:292).

En el régimen capitalista también el arquetipo de "paisaje" se universaliza y "ha hecho creer al ser humano que tiene control absoluto de su medio ambiente natural, el cual pasa a ser un recurso utilizable hasta su completo agotamiento. En esta visión, el paisaje pasa a ser un elemento de consumo y transacción, cuyo valor depende de los consumidores finales; vale decir, de cuánto están dispuestos a pagar los seres humanos por un paisaje de calidad" (Ojeda 2011:6). La voracidad capitalista construye, modifica y destruye territorios y no solo eso, estandariza atentando contra la integridad emocional de habitantes y visitantes. Esta frívola homogenización de las formas, producto de la universalización del mercado capitalista, ha impulsado la toma de conciencia del valor de lo diferente de los lugares que no han sido transformados y que aún signan la identidad de sus pobladores. Sin embargo, estos lugares acaban incorporados a la dinámica capitalista manteniendo su identidad o inventándoles otra que es vendida turísticamente y que 
genera utilidades al capital. Es el caso de las comunidades indígenas, los llamados "pueblos mágicos", los parques ecológicos, etc.

El ser humano vive sus relaciones materiales y espirituales en un territorio. Los cambios drásticos en el territorio habitado generan una ruptura entre su exterioridad y su interioridad, más allá de que la apropiación del territorio que habita se realice de manera paisajística o práctico-utilitaria. La ruptura se torna insoportable, aterradora.

\section{La apropiación subjetiva del territorio}

El concepto de territorio implica los conceptos de espacio y lugar. Éstos pueden ser concebidos de diversa manera dependiendo de la racionalidad teórica que se asuma. En la racionalidad teórica aristotélica el espacio que nos rodea es el lugar de los objetos sensibles, cuya unidad es expresada por su forma. El espacio vacío no existe porque "en un espacio vacío, no solo no existen lugares naturales, sino que no hay en absoluto lugares [...] Solo los cuerpos geométricos pueden ser 'colocados' en un espacio geométrico" (Koyré 2000:163). Espacio vacío es negación del espacio dado que su existencia está asociada a los cuerpos, por lo que no constituye una entidad diferente.

La estructura del espacio físico determina el lugar de los objetos que allí se encuentran. "Las formas, las modificaciones, los lugares, que son el fin del movimiento de los seres que se mueven, son inmobles, como la ciencia, el calor" (Aristóteles 2007:245). Los cuerpos se mueven con su espacio y con su tiempo y el cambio de lugar de un cuerpo es ocasionado por el movimiento. El universo es un lleno total; donde un cuerpo termina empieza otro. "Para Einstein, como para Aristóteles, el tiempo y el espacio están en el Universo y no el Universo en ellos" (Koyré 1994:68). El tiempo y el espacio están en los cuerpos y no los cuerpos en el tiempo y el espacio: "si es imposible que el lugar sea infinito, es imposible que lo sea él cuerpo mismo. Lo que está en algún lugar está en alguna parte, es decir, que está arriba o abajo, o en uno de los otros lugares [...] cada uno de estos lugares es un límite" (Aristóteles 2007:244). En la física cualitativa de Aristóteles el lugar natural es una exigencia teórica: un lugar para cada cosa y cada cosa en su lugar. Los cuerpos con sus lugares constituyen en conjunto un territorio. El lugar del territorio es el formado por el conjunto de lugares de los cuerpos que se encuentran en él.

Desde la racionalidad teórica platónica asumida por Newton, los cuerpos existen en el tiempo y en el espacio y pueden cambiar de lugar en el universo infinito y vacío. El espacio y el tiempo absolutos son verdaderos y matemáticos, en contraposición al espacio y tiempo sensibles que tienen carácter relativo y falso. La materia se encuentra separada del espacio y "el lugar-locus- es algo que está en los cuerpos y en el cual están a su vez los cuerpos. Y, del mismo modo que el movimiento es un proceso en el que los cuerpos cambian de lugares sin llevárselos con ellos, sino dejándolos para otros, la distinción entre espacios relativos y absolutos implica necesariamente la distinción entre movimiento relativo y absoluto y, vice versa" (Koyré 2005:154). Así, hay lugares absolutos y lugares relativos; los primeros están referidos al espacio absoluto y los segundos a los cuerpos que se encuentran en el espacio relativo. El espacio absoluto posee múltiples lugares que pueden ser ocupados por los cuerpos indistintamente; los cuerpos poseen un espacio, su espacio, que es relativo y que posee lugares.

Los cuerpos ocupan lugares en el espacio absoluto. "En el universo infinito de Bruno [...] los 'lugares' son perfectamente equivalentes $\mathrm{y}$, por consiguiente, perfectamente naturales para todos los cuerpos cualesquiera que sean" (Koyré 2000:188). Sin embargo, "todas las cosas cambian de lugar, porque al principio los corpúsculos de cada género se separan de los de otros géneros y van a reunirse en el lugar 
que les es propio bajo la influencia del movimiento de la sustancia que los contiene en su seno; y a continuación, cuando los corpúsculos de un género cesan de asemejársele para hacerse semejantes a otro género, son empujados por la sacudida que han recibido hacia el lugar ocupado por aquellos cuya semejanza han adquirido" (Platón 2009:339). Sin embargo, Platón en el diálogo del Timeo o de la naturaleza afirma la naturaleza esférica del universo que comprime los cuerpos e impide que quede un espacio vacío.

Desde una racionalidad teórica platónica, la apropiación subjetiva del paisaje en cuanto forma territorial es falsa, i) porque se trata de una idea construida a partir de las percepciones sensoriales, ii) porque se trata de la forma constituida con multiplicidad de formas de los objetos finitos (falsos) contenidos en el territorio del cual se hizo la construcción, iii) porque la forma de un territorio es temporal y, por tanto, falsa y, iv) porque la construcción de la idea se realiza en la inmediatez estética y no en la forma racional, es decir, en la episteme.

En Aristóteles, Marx y Einstein el tiempo y el espacio están en los cuerpos, en Platón y en Newton los cuerpos están en el tiempo y en el espacio y, en Kant tiempo y espacio son intuiciones sensibles a priori. Para Kant la totalidad absoluta no es más que una consideración puramente subjetiva y no producto de la imposibilidad empírica de llegar "por la progresión de la medida de las cosas del mundo sensible en el tiempo y en el espacio" (Kant 2008:89). El espacio es la forma a priori de la posibilidad de la representación de las cosas exteriores, en tanto que el tiempo "es la condición formal a priori de todos los fenómenos en general. [...] es una condición a priori de todo fenómeno en general y es condición inmediata de los fenómenos internos (de nuestra alma) y precisamente por ello condición inmediata también de los fenómenos externos" (Kant 2008:58).

La indeterminabilidad empírica del inicio y del fin del tiempo y el espacio, conduce a Platón y a Newton a suponerlos infinitos y absolutos y al traslado de las intuiciones empíricas a magnitudes observables. En cambio, Aristóteles, Einstein y Marx convierten el tiempo y el espacio en contenidos de las cosas en sí, tomando la intuición sensible como sensación y a ésta como percepción; es así que el tiempo cronométrico infinito y absoluto platónico-newtoniano pierde su carácter, se funde con el espacio y se torna cualidad de lo real en la categoría de modo de producción en Marx y en materia-energía en Einstein.

Espacio y tiempo son condiciones subjetivas necesarias de toda experiencia y de la intuición ante la cual "todos los objetos son meros fenómenos y no cosas dadas por sí en ese modo; de esos fenómenos pueden decirse por lo tanto a priori muchas cosas, en lo que toca a la forma de los mismos; pero no se puede nunca decir lo más mínimo de la cosa en sí misma, que está a la base de esos fenómenos" (Kant 2008:67). Los objetos son fenómenos, es decir, relaciones sujeto-cosa. "El espacio, pues, no puede presentarse absolutamente (por sí solo) como algo determinante en la existencia de las cosas, porque no es objeto alguno, sino solo la forma de objetos posibles. Las cosas, pues, como fenómenos determinan el espacio" (Kant 2008:281). Los objetos exteriores son representaciones sensibles en el espacio y en el tiempo y, por lo tanto, fenómenos y no cosas en sí.

Si el tiempo y el espacio son intuiciones sensibles a priori y no existencias externas al sujeto, el lugar es el sitio que ocupa un momento de la representación fenoménica. El "concepto del cambio y con él el concepto del movimiento (como cambio de lugar) no son posibles sino mediante y en la representación del tiempo; que si esa representación no fuese intuición (interna) a priori, no podría concepto alguno, fuere el que fuere, hacer comprensible la posibilidad de un cambio, es decir de un enlace de predicados contradictoriamente opuestos ( $v$. g. el ser en un lugar y el no ser esa misma cosa en el mismo lugar) en 
uno y en el mismo objeto. Solo en el tiempo pueden hallarse ambas determinaciones contradictoriamente opuestas en una cosa, a saber una después de otra" (Kant 2008:57).

El territorio habitado se encarna en el sujeto de manera físico-biológica y psico-social. Como exterioridad del sujeto, el territorio es su hábitat; como interioridad es contenido de la conciencia. El territorio se encarna subjetivamente en los sujetos en un proceso mediado por la conciencia social. El territorio en la conciencia del sujeto es mapa, símbolos, imágenes, prácticas. "El territorio es el locus de los deseos, demandas y reclamos de la gente para reconstruir sus mundos de vida y reconfigurar sus identidades a través de sus formas culturales de valorización de los recursos ambientales y de nuevas estrategias de reapropiación de la naturaleza" (Leff 2004:125). El mapa es una representación simbólica del territorio que implica una concepción platónica del tiempo y el espacio como lienzo vacío y pasivo. De este modo, habitantes del mismo territorio, poseedores de conciencia empírica, se apropian paisajísticamente de su territorio en tanto que otros, la inmensa mayoría, lo hace de manera práctico-utilitaria a veces fundida con magia y religión y rara vez de manera teórica o como representación artística. "Desde el reflejo. Es posible construir el paisaje, estimándolo como una construcción subjetiva generada por nuestra propia mirada, por lo que de alguna forma obliga a incorporarnos a ese determinado marco que se nos ofrece cargado de belleza o seducción. La cuestión es la distancia que se decide fijar para definir la implicación deseada bajo la demanda de cualquier requisito moral. El paisaje se construye sobre nosotros mismos, en nosotros mismos. La construcción del paisaje implica una mirada sobre la interioridad, como si la estructura de lugar se plegase sobre nosotros, activando todos y cada uno de los mecanismos que definen la arquitectura del paisaje, esas estructuras invisibles que conforman los sistemas espaciales del sentimiento y la emoción" (Gazapo y Lapayese 2010:12).

El lugar que el sujeto ocupa en las relaciones sociales de producción determina, en buena medida, la cantidad y la calidad de los referentes que se incorporan a su conciencia, por lo que la posibilidad de construcción paisajística de territorios está determinada por las experiencias estéticas del sujeto. Estudios, viajes, experiencias teatrales, cinematográficas, dancísticas, pictóricas, esculturales, arquitectónicas, musicales activan la sensibilidad artística y posibilitan la valoración estética de lo real. La constitución múltiple de las conciencias individuales impide la apropiación paisajística del territorio por todos sus habitantes, ya que en la mayoría de los casos la conciencia no posee referentes para realizarla. El sujeto prototípico de la sociedad capitalista es el ser humano embrutecido para el que el paisaje mostrado en los anuncios comerciales, en el cine, en libros y folletos o por televisión es una mercancía y no un medio de despliegue emocional. Pero, aunque ese ser humano enajenado no lo sepa, el territorio que habita es identitario más allá de sus características y de los modos de su apropiación, pero se trata de una identidad encarnada de manera múltiple entre los habitantes de un territorio y entre los extraños que lo contemplan.

Las diferencias en el territorio deseado son causa de conflictos sociales. Quienes se lo apropian paisajísticamente tienden a la conservación; quienes se lo apropian de manera práctico-utilitaria quieren circulación de mercancías, empleo, generación de plusvalía, de ahí que la lucha por la conservación del patrimonio paisajístico no se reduce a su sustrato material, sino que principalmente debe ser orientada a la acción pedagógica que garantice la valoración estética del territorio. Dice Álvarez Muñárriz: “Desde un punto de vista subjetivo un paisaje no solamente se ve y se contempla, sino que se siente, se asimila con todos los sentidos y penetra en nuestro cuerpo y nuestra mente produciendo ricos y variados sentimientos" (2011:59). Efectivamente, el territorio apropiado como paisaje desata emociones en el sujeto. Visión, oído, tacto y olfato se activan en la proyección estética del sujeto sobre el territorio. La vista 
es el primer medio de apropiación sensorial del territorio, pero el resto de los sentidos se integran al proceso.

La universalización del modo capitalista de producción ha ido modificando múltiples regiones del mundo en las que, además de la estandarización de las formas, ha incluido olores y sonidos. Es universalización de mercancías, hábitos, anhelos, objetos y formas de vida. Tener automóvil propio requiere de cochera, calles pavimentadas, señalización, carreteras, puentes, etc. Cuando se modifica algo en un lugar, cambian otros objetos. Se talan determinados árboles y con ellos se van insectos y aves asociados a ellos; se plantan árboles de otras especies y se atrae insectos y aves que cantan diferente, se usan determinados materiales de construcción de techos que modifican la temperatura y el sonido producido por la lluvia. "La globalización, la tecnología casi universal de los motores, está borrando la identidad sonora que en otras épocas tuvieron los paisajes. Los sonidos atmosféricos (la lluvia, el viento, el mar, la tormenta) pierden relieve en los grandes espacios construidos y las formas culturales del sonido se suceden y sustituyen velozmente. La mayor parte del esfuerzo para mantener la memoria histórica se dedica a los objetos construidos, las formas. Pero ¿cómo conservar los sonidos en trance de extinción?" (Durán 2007:49). Debido a que el paisaje se transporta sobre soportes visuales (fotografía, pintura, cine, literatura) se olvida la presencia de los olores y los sonidos.

El régimen capitalista surge históricamente con un reclamo territorial. Los Estados nacionales se constituyen con territorio, población y monopolio de la violencia y para ello crearon símbolos identitarios como la bandera, los héroes, el himno y el territorio. La diversidad territorial contenida en una nación implicó la conversión de la zona predominante en representante de la totalidad del país o bien aquel territorio poseedor de mayores peculiaridades. La burguesía hecha Estado creó todo un imaginario colectivo en el que incluyó el territorio.

El sujeto poseedor de referentes artísticos de manera suficiente puede construir figuras de pensamiento de carácter paisajístico con las que se deleita. No se trata de capturas momentáneas del territorio en fotografía o en película o usadas como motivo de un cuadro. Esta figura de pensamiento paisajística construida solo existe en la conciencia del sujeto y se trata de un constructo incomunicable. La sociedad le dice al sujeto qué es bello, qué es sublime, qué es feo, qué es un paisaje, pero la figura de pensamiento construida por el sujeto es comunicable descriptivamente de manera oral o escrita, solo cuando la apropiación posee carácter práctico-utilitario. No sucede así cuando se trata de una apropiación paisajística y el sujeto no posee la formación artística que le permita construir un discurso comunicable. Por el contrario, del mismo modo que al sujeto que le enseñaron a nombrar verde a un color determinado y que puede estar viendo azul y llamarle verde, quien realiza una apropiación empírica del paisaje puede suponer que construye una figura paisajística sin sentir emoción alguna.

Esto sucede en general con el arte. Los medios masivos de comunicación anuncian la exhibición de una colección hermosa de cuadros, muestran imágenes paisajísticas anunciando paquetes turísticos, promueven la asistencia masiva a espectáculos dancísticos o ponen de moda a un tenor o a una soprano. Asistir a esos espectáculos da prestigio social ya que se le considera "culto" a quien lo hace, aunque no le genere emoción alguna. La socialización comercial de modelos arquetípicos en el arte hace transitar a las obras de arte de generadoras de emociones a pruebas de poder económico disfrazado de alta cultura. Una de las actividades en las que más claramente se muestra esta situación es el turismo. Las imágenes generadas por el cine o para anuncios comerciales "forman el imaginario mítico que el turista occidental tiene en su cabeza; y si no se quiere crear frustración en el visitante, la realidad de la zona de destino se adapta a la imagen que se ha generado en la cabeza del turista" (Santacana y Serrat 2009:210). 
En el arte el artista dialoga con quien contempla su obra a través de ella. Es decir, el artista habla por medio de su obra; la obra es un texto que, como el alma platónica, contiene la totalidad grabada, pero que de ella solo se lee lo que el sujeto que la contempla le proyecta. Su contenido pareciera ser variante en cuanto genera múltiples lecturas, tantas como sujetos la leen, se trate o no de sujetos diferentes. Así sucede en el arte: hay creador, obra y espectador; en la contemplación paisajística territorial no hay creador, hay objeto, pero éste habla solamente por medio del sujeto.

El territorio es comercialmente explotado como paisaje sin que necesariamente todos los turistas vivan una experiencia estética en su contemplación. El turista compra el prestigio que genera visitar las pirámides de Egipto, las ruinas de Atenas, la Tierra Santa, el Vaticano, las Cataratas del Niágara o de Iguazú. Visita museos, realiza paseos por zonas de vegetación exuberante, contempla valles y montañas, pero lo contemplado no le dice nada. Por otra parte, es más fácil que un turista perciba la impronta cromática de los elementos naturales en el paisaje que quienes habitan ese territorio, pero la utilización del territorio como paisaje con fines turísticos lo pervierte. El promotor turístico establece los sitios de interés: museos, plazas, monumentos, edificios y territorios de acuerdo con criterios comerciales y no estéticos. El turista puede no percibir la belleza de un cuadro, de una escultura o de un edificio considerados obras de arte, pero visitarlos, verlos, lo hace sentirse culto y ser considerado así por los demás. Lo mismo sucede con los lugares considerados "paisaje" en los que el turista solo ve cosas, objetos al igual que el promotor turístico.

Si bien todas las formas de conciencia pueden establecer una relación contemplativa paisajística del territorio, ésta es abandonada de inmediato al transitar al ejercicio del modo de apropiación dominante en la forma de la conciencia del sujeto. Como afirma Zimmer: "La experiencia estética del paisaje significa una relación totalmente nueva del ser humano con la naturaleza. Ésta es muy diferente de la investigación científica y de la apropiación social de la naturaleza mediante el trabajo" (2008:29). Mientras que la apropiación empírica del territorio implica su transformación, la experiencia estética tiene lo dado como finalidad sin fin.

El primer contacto que el científico dotado de referentes artísticos establece con el territorio es de carácter estético, es decir, establece una relación paisajística. "Frente al paisaje, el observador no adopta una aproximación científica, sino que sufre una reacción estética que le produce emociones y le despierta sentimientos. Esa sensación sin embargo no es nunca arbitraria, sino que en ella juegan un papel primordial los referentes que maneja el observador y su entendimiento de la situación. La aproximación al paisaje emociona combinando en el aprecio sentimientos y entendimiento" (Español 2008:204). La intencionalidad cognitiva científica puede tener un origen estético paisajista, pero el desafío principal consiste en convertir en objeto holístico tanto lo estético como su sustrato material.

\section{La apropiación científica del paisaje}

Dado que los referentes constitutivos de la conciencia provienen de la sociedad en la que el sujeto se constituye, "el paisaje es, en primer lugar, el producto de una operación perceptiva, es decir, una determinación sociocultural" (Roger 2013:139). Si la naturaleza no es bella en sí, es decir, si la belleza no está en los objetos que la constituyen, el paisaje es un constructo cultural producto del concurso de referentes socializados e incorporados a la conciencia de los individuos.

La apropiación paisajística del territorio surge como representación artística pictórica durante la Edad Media. Los referentes artísticos plasmados en la pintura paisajística fueron aprendidos por quienes la contemplaron y utilizados en la experiencia estética contemplativa del territorio. Los referentes 
paisajísticos nacen en la forma artística de apropiación de lo real y de ahí se van incorporando a otras formas de la conciencia como experiencias estéticas contemplativas. Esto significa que el territorio no siempre ha sido apropiado como paisaje y que antes de su representación pictórica la apropiación correspondía a lo bello natural, si bien históricamente se han ido gestando los modos de apropiación de lo real, siendo el empírico el que ha acompañado al ser humano a lo largo de la historia. "El paisaje tiene, pues, una base material concreta, referida no a nociones más abstractas como espacio, área o suelo, sino a territorio, es decir, el espacio geográfico entendido como marco de vida, como espacio contextual de los grupos sociales. Asimismo, como hecho territorial el paisaje tiene también escalas diferentes, que afectan tanto a su estudio, como al sentido y alcance de las determinaciones de ordenación y de proyecto paisajístico" (Mata 2008:156).

Un individuo dotado de referentes artísticos puede apropiarse paisajísticamente de un territorio con una enorme carga emocional y en cambio pasarle totalmente inadvertido otro territorio, del mismo modo que sucede con la música, la pintura o con cualesquiera otras expresiones artísticas. También sucede que un artista sea insensible a objetos de arte de un género distinto al de su ocupación o a algunos de ellos. Es necesario que el objeto posea las cualidades que referencialmente existen en el sujeto para que se establezca una relación estética, solo que, en el caso del territorio, las cualidades no son artísticas, pero los referentes con los que se percibe el territorio sí lo son. "Para que existan paisajes deben existir una serie de elementos objetivos que los compongan, pero sobre todo es necesario alguien que los perciba, los viva y les otorgue un significado" (Álvarez Muñárriz 2011:69).

Los sujetos durante toda su vida construyen territorio sin que su participación implique una apropiación paisajística de los territorios que habitan ni de territorios ajenos. Es decir, la historia y la cultura se encarnan de manera diferencial en los sujetos, de modo tal que la sensibilización paisajística no necesariamente es depositada en el sujeto. Martínez afirma que "el paisaje es donde se vive y sobrevive y ello conlleva tanto la utilidad como la calidad" (2014:328) y no es así. No se vive en el paisaje, se vive en un lugar, en un territorio. El sustrato material del paisaje es territorio, ecosistema, geosistema, ambiente, etc. Se requiere no confundir el paisaje como proceso de construcción subjetiva con la investigación científica del mismo y su investigación científica no debe confundirse con la dimensión empírica de su existencia. El paisaje es un constructo estético subjetivo producto de la experiencia contemplativa de un territorio que implica sentimientos intensos como los vividos en la contemplación de una obra de arte. La investigación científica del paisaje es una experiencia teórica que pretende generar el conocimiento de las condiciones en las que se realiza una experiencia estética, sin dejar de ser teórica y sin fundirse jamás con la experiencia estética, dado que las experiencias (teóricas, empíricas, religiosas, estéticas) son excluyentes. La teoría construye sus objetos de investigación y éstos no son objetos empíricos, aunque, en ocasiones, se les trate como iguales.

La percepción estética de un territorio puede conducir a las comunidades que lo habitan a luchar por su preservación, pero, si se acepta la concepción de que todo territorio es paisaje, lo mismo da que se trate de un tipo de territorio o de otro ya que, al final de cuentas, todo es paisaje. Si todo es paisaje, no hay por qué preocuparse por la desaparición de algunos de ellos ya que en su lugar surgen otros.

La experiencia estética contemplativa paisajística no se activa por motivación sensorial, dado que la conciencia de los sujetos opera apriorísticamente y que lo sentido por diferentes sujetos se realiza de manera inconmensurable, más allá del convencionalismo denotativo de los vocablos de uso común para denominar las sensaciones. Si el color, el olor o el sabor pertenecen a los objetos y no a los sujetos, ¿cómo se explica que se hayan descubierto sonidos imperceptibles por el oído humano y colores percibidos por 
el ser humano que no son percibidos por algunos animales? La propuesta de captación sensorial del paisaje enfrenta esta dificultad: tres sujetos observan un territorio; el territorio es el mismo, aunque fuese observado por 100 o por 1000 sujetos, pero ¿todos ven lo mismo?, ¿todos construyen en su conciencia la misma imagen de ese territorio? La respuesta es no.

Los problemas implicados en la percepción de lo real llevaron a Platón a considerar a los sentidos como impedimento de captación de lo verdadero y a proponer a la reflexión racional como camino a la verdad. De conformidad con este planteamiento, la percepción conduce a la construcción de figuras de pensamiento necesariamente falsas en el sentido de su no correspondencia con la realidad aludida en ellas. Sin embargo, mientras que lo sentido no es comunicable, las figuras de pensamiento producto de la percepción sí lo son, de ahí que sea factible su investigación científica. Los referentes sensoriales son incorporados a la conciencia de conformidad con la estructura de ésta y no como reproducción subjetiva de lo real, por lo que cada figura de pensamiento es condensación de la conciencia total. A eso se debe que las figuras de pensamiento sean producto del concurso de referentes sensoriales, mágico-religiosos, artísticos y teóricos.

Entre los teóricos del paisaje hay quienes consideran la ininteligibilidad racional de la subjetividad y, por lo tanto, la imposibilidad de conocerla científicamente, a diferencia del mundo objetivo (material) que puede ser sometido a análisis y reconstrucción. De esta manera, las ciencias sociales y las humanidades no son científicas dado que sus objetos de estudio son subjetivos.

Si una conciencia concibe lo real como racional lo capta racionalmente; si se concibe de manera mágicoreligiosa, se percibe de manera mágico-religiosa y así sucesivamente. Por ejemplo, Galileo concebía lo real como estructuras matemáticas, pero como los sentidos son incapaces de captar la estructura geométricomatemática de los objetos, se hace necesaria la medición para acceder a su verdad, es decir, al conocimiento de su estructura matemática. Esto plantea de una manera distinta el problema: la racionalidad no es atributo de lo real, sino de la conciencia, por lo que el modo de apropiación precede a la apropiación. Lo real puede ser apropiado de distintas maneras. Los objetos exteriores no son teóricos, mágicos, religiosos, artísticos o práctico-utilitarios, la manera de apropiárselos sí lo es. Visto así el problema, el paisaje no es inteligible racionalmente si su existencia se considera exclusivamente como figura de pensamiento y, por tanto, subjetiva. Roger plantea: “Conviene, pues, distinguir sistemáticamente lo que tiene relación con el paisaje y lo que depende del medio ambiente. Esto no quiere decir que no haya que articular ambos términos, muy al contrario, pero la articulación pasa por la previa disociación de los mismos. Contra los ecólogos, diré que un paisaje no puede reducirse nunca a un ecosistema y, contra los geógrafos, diré que menos aún puede reducirse a un geosistema. En definitiva, el paisaje no es un concepto científico y no existe ni puede existir una ciencia del paisaje, lo que, evidentemente, no significa que no pueda mantenerse un discurso coherente respecto a este tema" (Roger 2008:75).

Roger equivoca los términos. Geosistema, ecosistema y paisaje son conceptos que pertenecen a corpus teóricos diferentes e inconmensurables, por lo que la articulación planteada por él es imposible: se piensa ecosistema, geosistema, paisaje, más no paisaje ecosistémico, paisaje geosistémico. El paisaje como figura de pensamiento es objeto de la sociología, la antropología, la psicología y la semiótica. La producción de obras de arte es arte; el estudio de la producción artística es estética. La producción artística es realizada por sujetos cuya conciencia posee la forma artística, en tanto que el estudio de la producción artística lo realizan sujetos poseedores de conciencia teórica. El creador de arte puede poseer referentes teóricos del mismo modo que posee referentes empíricos y mágico-religiosos, pero todos ellos están subordinados al modo artístico de apropiación de lo real. Lo mismo sucede con el científico que estudia la producción 
artística, solo que éste necesariamente debe poseer los referentes artísticos necesarios para identificar las obras de arte, a diferencia del artista que no requiere de una fuerte carga de referentes teóricos para realizar su obra.

La investigación estética del paisaje es realizable en el campo de la pintura, la fotografía, el cine y la literatura dado que se trata de representaciones artísticas paisajísticas, de ahí que el esteta del paisaje requiera estar dotado de una buena dosis de referentes artísticos que le permitan su identificación. Sin embargo, la experiencia artística contemplativa paisajística no es objeto de estudio del esteta, ya que la estética solo estudia los productos de conciencias artísticas, más no la interiorización contemplativa del arte en sujetos poseedores de conciencia empírica, teórica, artística o mágico-religiosa.

El momento histórico diferencial de generación de los conceptos de paisaje y medio ambiente tampoco son en sí problemáticos; sí lo es la pertenencia a racionalidades teóricas diferentes. Dice Roger: "Se considera habitualmente que el paisaje forma parte del medio ambiente, del que sería uno de sus aspectos, una de sus dimensiones, y que, por tanto, también merece ser protegido, del mismo modo que nos preocupamos por salvaguardar el mencionado medio ambiente. Sin embargo, esta postura, que parece sensata, es discutible. Hablando en propiedad, el paisaje no forma parte del medio ambiente. Este último es un concepto reciente, de origen ecológico, $y$, por esta razón susceptible de tratamiento científico. En cuanto al paisaje, es una noción más antigua (data, como acabamos de ver, de finales del siglo XV o, como mucho, principios del XVI), de origen artístico (la pintura flamenca) y que, como tal, compete a un análisis estético" (Roger 2008:75).

La experiencia paisajística contemplativa no ha sido suficientemente tratada por la estética y ha sido abordada por la sociología, la antropología, la semiótica y la psicología despojada de criterios estéticos. En particular, la semiótica es una teoría con altas posibilidades de teorización tanto de la dimensión subjetiva de la apropiación social del territorio y de su papel activador de la relación social entre el ser humano y la naturaleza. Busquets considera que la semiótica puede aplicarse al paisaje tomando en cuenta la semiosis, es decir, "el proceso a través del cual el perceptor atribuye significado a los signos. Por otra parte, la atribución de significados a los signos de un paisaje por parte de un perceptor no se puede desligar de la existencia de valores y actitudes personales que suponen una fuerte carga ideológica y emocional en tanto que los individuos siempre actúan dentro de un cierto contexto social y de una determinada cultura. Así pues, para que un componente del paisaje tenga algún significado y pueda ser objeto de interpretación, debe haber al menos una persona capaz de percibirlo, estructurarlo y asignarle significado y el significado atribuido no se puede desvincular de su contexto humano y territorial" (Busquets y Cortina 2009:155). Gaona Pisonero aplica la semiótica para estudiar el sentimiento identitario de una comunidad y afirma: "Dentro de toda la compleja experiencia de salud, nos centramos en la reafirmación de las subjetividades de los habitantes del municipio de Campo de Níjar, que se hace a partir del impulso y sentidos que concede su territorio, como especial lugar de continuum sígnico. Desde las transferencias sígnicas del territorio al sujeto, se reformula el nivel más profundo de los símbolos identitarios" (Gaona 2014:233).

Cuando la apropiación del territorio es paisajística, el sujeto construye una figura estética desatándosele emociones que hacen de la contemplación una penetración del objeto en el sujeto. "Fue la modernidad romántica la que introdujo en la cultura occidental la percepción y la valoración del paisaje, a través sobre todo de la mediación estética. En la concepción romántica, la naturaleza es entendida, vista y sentida, como una totalidad viva y organizada, la conexión sin fin de las cosas, un todo del que forma parte el ser humano y donde los lugares cobran significado. La comprensión romántica del mundo entraña, además, la experiencia estética como mediación del conocimiento. Nacía así la 'naturaleza-paisaje', entendiendo el 
paisaje como naturaleza estéticamente presente, que se muestra al ser que la contempla con sentimiento. La mirada, por así decirlo, se carga de teoría y la contemplación teórica se convierte en espectáculo estético" (Nogué 2007:15).

La investigación científica del paisaje como totalidad existente en la subjetividad implica el estudio de la estructura de la conciencia, los estereotipos paisajísticos sociales, la identificación de los referentes paisajísticos integrados a la conciencia, el estudio de las emociones desatadas y el análisis de las figuras paisajísticas de pensamiento construidas. Como plantea Bertrand: "El paisaje no es una molécula, ni un anticlinal. No solo contiene una parte irreductible de sentimientos, emociones, incluso de razones sinrazones, sino que es precisamente este atributo íntimo el que suele ser fuertemente, y justamente, reivindicado en la mayor parte de los proyectos de paisaje. Forma parte del protocolo. Esta dimensión estetizante distingue el paisaje de otras nociones o conceptos tales como medio ambiente, ecosistema 0 geosistema" (Bertrand 2008:22).

El paisaje no es todo lo que está en un territorio, no es una totalidad objetual; es una forma total constituida por las formas de los objetos concretos existentes en un territorio; es un continuum de formas, no de cosas ni la extensión de la forma de un objeto. El paisaje es la figura estéticamente construida; el fragmento territorial convertido en figura estética pensada, de ahí que casi siempre los paisajes existan inconscientemente en los sujetos que forman parte de un territorio como meras nociones. El impedimento de apropiación paisajística se debe a que la acción del ser humano en la naturaleza está mediada por las relaciones sociales de producción y las cosmovisiones creadas por la clase dominante en cada momento histórico. La opresión social del sujeto es, sobre todo, subjetiva.

\section{Conclusiones}

La entidad comunitaria se apropia del territorio concibiéndose parte indiferenciada de la naturaleza. El territorio es el lugar ocupado periódica o permanentemente por la comunidad; en él la comunidad satisface sus necesidades materiales y espirituales y éstas se van incrementando en la medida en la que van surgiendo clases sociales y unas de ellas, las dominantes, requieren de acumulación de riqueza y consumo conspicuo. El crecimiento de la población humana y el consumo conspicuo de las clases sociales dominantes se da en un proceso de dominio creciente de la naturaleza por el ser humano. El territorio es cada vez más producto de la acción humana y el ser humano el más importante generador de su morfología. La universalización del régimen capitalista se tradujo en mercantilización del territorio y en derecho de su propietario para conformarlo según su deseo. El capitalismo destruye, transforma y construye territorios conforme a modelos arquetípicos de paisaje impuestos culturalmente a la población, los cuales permiten la venta de experiencias contemplativas territoriales. El territorio se encarna subjetivamente en los sujetos y constituye el lugar en el que se realizarán proyectos y se viven nostalgias y recuerdos. Independientemente del modo en el que la apropiación del territorio se realice, el territorio vive en el sujeto, constituye el lugar de despliegue de su existencia y posee carácter identitario. La mutilación, alteración o destrucción de un territorio atenta contra la existencia del sujeto. Aunque la apropiación del territorio sea predominantemente práctico-utilitaria, la existencia de referentes artísticos en todas las formas de la conciencia hace posible la experiencia paisajística contemplativa.

El paisaje surge durante el capitalismo mercantil. La apropiación paisajística del territorio iniciada con la representación artística pictórica en la Edad Media, propia de la forma artística de la conciencia, transitó a experiencia estética contemplativa realizable desde cualquier forma de conciencia. Después, algunas racionalidades teóricas suprimieron la relación contemplativa y denominaron "paisaje" al territorio, 
suprimiendo al sujeto en aras de la objetividad científica, sin percatarse de que se trata de un objeto diferente. La experiencia paisajística es una relación sujeto-objeto, el territorio es su sustrato material. Así, la geografía llama paisaje al geosistema; la ecología al ecosistema; la sociología, la antropología y la semiótica a la figura de pensamiento con la que el sujeto se apropia del territorio, sea paisajística o no. Sin embargo, el paisaje no es el sustrato material de un territorio, sino la experiencia estética del sujeto con el territorio.

El paisaje concebido como figura de pensamiento resultante de una relación estético-contemplativa entre sujeto y territorio, puede ser interpretada aristotélicamente como producto de las sensaciones emanadas por un bello territorio y captadas por un sujeto dotado de los referentes artísticos requeridos para ello, o de manera platónica como proyección de contenidos de la conciencia sobre un territorio o como idealidad despojada de referentes externos al sujeto. En ambos casos es necesaria la existencia de lo bello o lo sublime en el territorio y la existencia de referentes artísticos en la conciencia del sujeto para que la experiencia paisajística se realice. Sin embargo, aunque las conciencias adquieran una forma determinada, cada conciencia individual es única e irrepetible. Esto relativiza la valoración de lo bello.

\section{Agradecimientos}

El presente trabajo es un producto del Proyecto IPN SIP: 20180090 denominado: Idea de lo bello y estética del paisaje.

\section{Bibliografía}

Álvarez Muñárriz, L. 2011. La categoría de paisaje cultural. AIBR 6(1): 57-58.

http://www.redalyc.org/articulo.oa?id=62321332004

Aristóteles. 2007. Metafísica. México: Porrúa.

Bertrand, G. 2008. "Un paisaje más profundo». De la epistemología al método. Cuadernos Geográficos 43: 17-27. http://www.redalyc.org/articulo.oa?id=17104302

Busquets, J. y Cortina, A. 2009. Gestión del paisaje. Barcelona: Ariel.

Durán, M. 2007. Paisajes del cuerpo, pp. 27-62. En: J. Nogué. La construcción social del paisaje. Madrid: Biblioteca Nueva.

Español, I. 2008. El paisaje como percepción de las dinámicas y ritmos del territorio, pp. 203-225. En: J. Maderuelo. Paisaje y territorio. Madrid: Abada.

Fernández Álvarez, R. 2013. Metodología para la caracterización y diferenciación de las unidades de paisaje de un espacio de montaña: las sierras de Béjar y Candelario. Boletín de la Asociación de Geógrafos Españoles 62: 101-127. https://doi.org/10.21138/bage.1571

Gaona, C. 2014. Sujetos del dolor, territorio de la dignidad. Methaodos 2(2): 227-243. http://www.methaodos.org/revista-methaodos/index.php/methaodos/article/view/54

Gazapo, D. y Lapayese-Luque, C. 2010. ¿Desde dónde... se construye el paisaje? Arquitectura, Urbanismo, Sostenibilidad 7: 12-15. http://www.redalyc.org/articulo.oa?id=281722846003

Gómez, J. 2008. La mirada del geógrafo sobre el paisaje: del conocimiento a la gestión, pp. 11-59. En: J. Maderuelo. Paisaje y territorio. Madrid: Abada. 
Kant, I. 2008. Crítica de la razón pura. Buenos Aires: Centro Editor de Cultura.

Koyré, A. 1994. Pensar la ciencia. Barcelona: Paidós.

Koyré, A. 2000. Estudios de historia del pensamiento científico. México: Siglo XXI.

Koyré, A. 2005. Del mundo cerrado al universo infinito. México: Siglo XXI.

Leff, E. 2004. Racionalidad ambiental: la reapropiación social de la naturaleza. México: Siglo XXI.

Martínez, E. 2014. Teorías del paisaje, pp. 415-426. En: J. Arnáez Vadillo, et al. Geoecología, cambio ambiental y paisaje: homenaje al profesor José María García Ruiz. Logroño: Consejo Superior de Investigaciones Científicas.

Mata, R. 2008. El paisaje, patrimonio y recurso para el desarrollo territorial sostenible. Arbor 184(729): 155-172. https://doi.org/10.3989/arbor.2008.i729.168

Milani, R. 2008. Estética y crítica del paisaje, pp. 45-66. En: J. Nogué. El paisaje en la cultura contemporánea. Madrid: Biblioteca Nueva.

Nogué, J. 2007. La construcción social del paisaje. Madrid: Biblioteca Nueva.

Nogué, J. 2008. El paisaje en la cultura contemporánea. Madrid: Biblioteca Nueva.

Nogué, J. 2011. Otros mundos, otras geografías. Paisajes residuales. Revista da ANPEGE 7(1): 3-10 https://doi.org/10.5418/RA2011.0701.0001

Ojeda, C. 2011. Estado del arte en las conceptualizaciones del paisaje y el paisaje urbano. GeoGraphos 2(7): 1-17. https://doi.org/10.14198/GEOGRA2011.2.07

Platón. 2009. Diálogos. México: Porrúa.

Roger, A. 2008. Vida y muerte de los paisajes, pp. 67-85. En: J. Nogué. El paisaje en la cultura contemporánea. Madrid: Biblioteca Nueva.

Roger, A. 2013. Breve tratado del paisaje. Madrid: Biblioteca Nueva.

Santacana, J. y Serrat, N. 2009. La dimensión patrimonial del paisaje, pp. 201-220. En: J. Busquets. Gestión del paisaje. Barcelona: Ariel.

Zimmer, J. 2008. La dimensión ética de la estética del paisaje, pp. 27-44. En: J. Nogué. El paisaje en la cultura contemporánea. Madrid: Biblioteca Nueva.

Zusman, P. 2008. Epílogo. Perspectivas críticas del paisaje en la cultura contemporánea, pp. 275-298. En: J. Nogué. El paisaje en la cultura contemporánea. Madrid: Biblioteca Nueva.

Recibido el 26 Ago 2018

Aceptado el 16 Nov 2018 